Check for updates

Cite this: J. Mater. Chem. A, 2019, 7, 5656

Received 26th October 2018 Accepted 5th February 2019

DOI: $10.1039 / c 8 t a 10328 c$

rsc.li/materials-a

\section{Laser-induced breakdown spectroscopy for the quantitative measurement of lithium concentration profiles in structured and unstructured electrodes}

\author{
Peter Smyrek, (D) *ab Thomas Bergfeldt, ${ }^{a b}$ Hans Jürgen Seifert ${ }^{a}$ \\ and Wilhelm Pfleging (D) ab
}

Quantitative chemical mapping of battery electrodes is a rather new post-mortem analytics method for identifying and describing chemical degradation processes in lithium-based battery systems. In consideration of future applications, the development of lithium-ion batteries is quite essential in order to meet requirements such as improved cell lifetime ( $>5000$ cycles), high energy density at the cell level $\left(>250 \mathrm{~W} \mathrm{~h} \mathrm{~kg}{ }^{-1}\right.$ ), reduced charging times (<15 min), high power density $\left(>2500 \mathrm{~W} \mathrm{~kg}^{-1}\right)$, and reduced manufacturing costs $(<150 \$$ per $\mathrm{kW} \mathrm{h})$. One novel approach that can handle a contemporaneous enhancement of energy and power density is the development of a novel cell design, mandated in a threedimensional (3D) arrangement. This so-called "3D battery concept" enables electrode configurations with improved lithium-ion diffusion kinetics and provides reduced mechanical stresses which could arise during battery cycling. Within this study, laser-induced breakdown spectroscopy (LIBS) was applied quantitatively as a powerful analytical tool in order to study chemical degradation mechanisms and the impact of 3D electrode architectures on lithium distribution. It could be shown so far that free-standing electrode architectures can provide new lithium-insertion pathways which enhance the capability of the electrode material to operate under abuse conditions. Elemental mapping and elemental depth-profiling were applied for characterizing the electrode as a function of cell lifetime and architecture. For the first time, it was demonstrated that LIBS can be used to quantitatively describe lithium distribution in a 3D battery with specific design parameters. Finally, new scientific findings regarding electrochemically driven degradation and aging mechanisms of laser-structured, embossed, and unstructured NMC electrodes were explored.

\section{Introduction}

Lithium-ion batteries (LIBs) provide prominent advantages and can be characterized by their high volumetric and gravimetric energy density, high power capability, high efficiency, and long cycle life. ${ }^{1-5}$ More recently, LIBs have been recommended as one of the most promising power sources for sustainable transport applications such as for hybrid electric vehicles, plug-in hybrid electric vehicles, or full electric vehicles, as well as for electrochemical storage systems in renewable energy plants. ${ }^{6-12}$ In terms of energy and power density, it was reported that lithiumion seems to be the only energy storage technology with the potential to fulfill the future requirements of the automotive industry. ${ }^{13}$ However, it is important to emphasize that the costs and performance limitations of the present lithium-ion batteries hinder their fast implementation and acceptance in electric vehicles and their efficient use in combination with renewable energy sources. ${ }^{14}$ For these reasons, a major focus in

${ }^{a}$ Karlsruhe Institute of Technology (IAM-AWP), Germany. E-mail: peter.smyrek@kit. edu; thomas.bergfeldt@kit.edu; hans.seifert@kit.edu; wilhelm.pfleging@kit.edu

${ }^{b}$ Karlsruhe Nano Micro Facility (KNMF), Karlsruhe, Germany recent research is the enhancement of battery performance by simultaneously reducing production and material costs. On the cathode side and inspired by the commercial success of $\mathrm{Li}\left(\mathrm{Ni}_{1 / 3} \mathrm{Mn}_{1 / 3} \mathrm{Co}_{1 / 3}\right) \mathrm{O}_{2}$, scientists developed new nickel-enriched layered oxides with various chemical compositions ( $\mathrm{Li}\left(\mathrm{Ni}_{1-x-y} \mathrm{Mn}_{x} \mathrm{Co}_{y}\right) \mathrm{O}_{2}$ ) for increasing the reversible capacity. ${ }^{15}$ Concurrently, the fabrication of electrodes with film thicknesses up to $320 \mu \mathrm{m}$ was demonstrated elsewhere, ${ }^{\mathbf{1 6}}$ leading to a smaller amount of inactive material, i.e., a reduced cell weight and an increased LIB energy density could be achieved. However, the application of electrodes with film thicknesses beyond the state of the art (electrode thickness $>100 \mu \mathrm{m}$ ) in lithium-ion cells affects the mechanical integrity of the film and decelerates lithium-ion diffusion kinetics during electrochemical cycling. ${ }^{17}$ One promising approach for enabling battery operation with high energy and high power density at the same time is the development of an advanced threedimensional (3D) lithium-ion electrode architecture maintaining short lithium-ion transport distances. ${ }^{18}$ The 3D battery concept enables high power and energy density, high rate capability, enhanced cycle lifetime, and reduced processing time for the cost-intensive electrolyte filling. ${ }^{19-21}$ Additionally, it 
is important to correlate the $3 \mathrm{D}$ architectures with electrochemical and chemical data. One essential electrode parameter is its porosity, which has a strong impact on cell performance, wettability, and cell degradation. ${ }^{22}$ The accurate adjustment of pore size distribution at the micro- and nano-scale and the degree of compression during calendering influence the electrical conductivity, the strength of coating adhesion between the composite material and the current collector, and finally the electrochemical performance of lithium-ion cells. ${ }^{22-24}$ In a very recent approach, it was shown that laser structuring can be applied for composite electrodes such as $\mathrm{LiFePO}_{4}, \mathrm{LiMn}_{2} \mathrm{O}_{4}$, or $\mathrm{Li}\left(\mathrm{Ni}_{x} \mathrm{Mn}_{y} \mathrm{Co}_{z}\right) \mathrm{O}_{2}$, with film thicknesses in the range of 50 to $250 \mu \mathrm{m} .{ }^{25-27}$ It could be clearly demonstrated that laser-structured electrodes can significantly improve cell lifetime, liquid electrolyte wetting behavior, specific capacity, and cycle retention. For the analysis of degradation mechanisms related to electrode topography and porosity, the investigation of lithium distribution can provide a suitable approach. For this purpose, quantitative elemental mapping and depth-profiling of the entire 3D electrode was investigated by laser-induced breakdown spectroscopy (LIBS). LIBS is an analytical tool used to obtain post-mortem information about the chemical composition of electrodes, from the surface down to the current collector interface. It has great potential to enable advanced fundamental studies on 3D electrode architectures for discovering their impact on performance enhancement regarding lifetime and capacity under abuse conditions and as a function of electrochemical cycling parameters. In the field of lithium-ion batteries, LIBS has been applied so far for studying the variations in chemical composition related to solid-state electrolytes, binder distribution in electrodes and interfacial layers. ${ }^{28-30}$ In preliminary studies the lithium distribution in thick film lithium nickel manganese cobalt oxide $\left(\mathrm{Li}\left(\mathrm{Ni}_{1 / 3} \mathrm{Mn}_{1 / 3} \mathrm{Co}_{1 / 3}\right) \mathrm{O}_{2}\right)$ electrodes is investigated post-mortem by LIBS. ${ }^{31,32}$ It could be shown that there is a change in Li distribution by introducing a 3D electrode design with free-standing micro-pillars. Nevertheless, the electrode design shown in ref. 31 was related to a real 3D electrode with close contact of the free-standing structures. The gap between two micro-pillars is about $20-40 \mu \mathrm{m}$ which is below the lateral resolution limit of the applied LIBS configuration. Therefore, for studying the impact of the contour or sidewall of the laser generated pillars, it was necessary to move from the "real" to a "model" electrode design. In the current approach, it was possible to use LIBS to characterize single micro-pillars without having any influence on the surrounding electrode material. This finally enabled us to describe quantitatively the lithium distribution with rather high accuracy. A chemical image of NMC cathodes will be presented, covering parameters such as electrode porosity and 3D topography. To our knowledge, this is quite a new analytic approach regarding post-mortem quantitative elemental mapping and elemental depth-profiling of lithium in 3D electrode architectures for LIBs.

\section{Experimental}

\section{Electrode fabrication}

The manufacturing route to composite cathodes used in this work can be separated into four processing steps: slurry preparation, coating, drying, and calendering. Each processing step has a strong impact on the electrode quality and finally on the electrochemical performance. Slurry preparation was carried out by adjusting the weight proportion to $90 \mathrm{wt} \%$ of the active material lithium nickel manganese cobalt oxide (Li(NiMnCo) $\mathrm{O}_{2}$, Ni : Mn : $\mathrm{Co}=1: 1: 1$, NMC, MTI Corporation, USA), 5 wt $\%$ of polyvinylidene fluoride binder (PVDF, MTI Corporation, USA) and $5 \mathrm{wt} \%$ of conductive additive (Timcal Super C65, MTI Corporation, USA). For the fabrication of one cathode sheet, $50 \mathrm{~g}$ of NMC, $2.8 \mathrm{~g}$ of PVDF, and $2.8 \mathrm{~g}$ of Timcal Super C65 were used. The active material was investigated related to its particle size distribution, offering a mean value of $9.89 \mu \mathrm{m}$ (Laser Scattering Particle Size Analyzer LA-950, Horiba Ltd., Japan). Additionally, the active powder exhibits a BET (Brunauer-Emmett-Teller) surface area of $0.38 \mathrm{~m}^{2} \mathrm{~g}^{-1}$ (Gemini VII 2390 a, Micromeritics Instrument Corporation, USA) and a material density of $4.6 \mathrm{~g} \mathrm{~cm}^{-3}$. Regarding the mixing procedure, first PVDF was dissolved in $30 \mathrm{~mL} \mathrm{~N}$-methyl-2-pyrrolidone (NMP) by magnetic stirring. Subsequently, NMC and Timcal Super C65 were added into the polymeric solution in the dry state. Another amount of NMP $(25 \mathrm{~mL})$ was added and the resulting slurry was then mixed (MSK-SFM-7, MTI Corporation, USA) in a vacuum atmosphere for two hours, indicating a homogeneous dispersion of the particles. Eventually, rheological investigation such as viscosity measurements were performed for characterizing the cathode slurry with respect to its flow behavior, coating control and avoidance of particle agglomeration. Subsequently, coating was performed using a tape-casting film coater equipped with an integrated heating lid (MSK-AFA-L800-H, MTI Corporation, USA). By adjusting the doctor blade gap, i.e., the distance between the aluminum current collector $(20 \mu \mathrm{m}$ in thickness) and the doctor blade edge, NMC thick films were fabricated with a film thickness of $140 \mu \mathrm{m} \pm 6 \mu \mathrm{m}$. In this work, a doctor blade gap of $450 \mu \mathrm{m}$ was used. The tape-casting process was performed at room temperature by applying a constant coating speed of $10 \mathrm{~mm} \mathrm{~s}^{-1}$. Next, the wet film was dried at $70{ }^{\circ} \mathrm{C}$ in order to remove the solvent from the electrode. A porosity of $54 \% \pm 3 \%$ could be estimated for each NMC thick film. The corresponding calculation is described elsewhere. ${ }^{\mathbf{3 1}}$ Finally, the electrodes were calendered using a compact hot rolling press (Precision $4^{\prime \prime}$ Hot Rolling Press/Calender, MTI Corporation, USA) with a roll temperature of $58{ }^{\circ} \mathrm{C}$. The rolling speed was maintained at $8 \mathrm{~mm} \mathrm{~s}^{-1}$ and the porosity of $35 \% \pm 3 \%$ could be adjusted. NMC electrodes with a thickness of $100 \mu \mathrm{m} \pm 3 \mu \mathrm{m}$ were fabricated for further investigations such as electrochemical characterization and post-mortem chemical analysis.

\section{Generation of free-standing architectures by ultrafast laser structuring and embossing}

Fig. 1 shows a schematic diagram of a femtosecond laser structuring process for the generation of micro-pillars in thick film NMC electrodes. The electrodes were structured using a laser micromachining workstation (PS450-TO, Optec s.a., Belgium) equipped with an ultrafast fiber laser (Tangerine, Amplitude Systèmes, France). Free-standing 


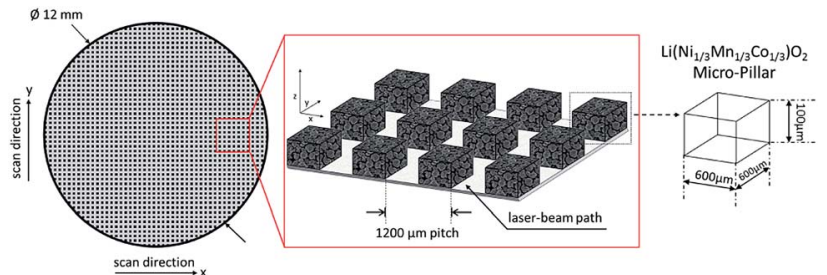

Fig. 1 Schematic diagram of fs-laser generated 3D architectures (micro-pillars) in thick film NMC electrodes.

micro-pillars were formed with a cubical shape of $600 \mu \mathrm{m} \times$ $600 \mu \mathrm{m} \times 100 \mu \mathrm{m}$ by removing the composite material down to the current collector. During processing, the laser pulse duration was set to 380 fs. The wavelength was adjusted to $515 \mathrm{~nm}$ and a repetition rate of $500 \mathrm{kHz}$ was applied. Freestanding micro-pillars were generated with a pitch distance of $1200 \mu \mathrm{m}$ using an average laser power of $1.45 \mathrm{~W}$. The laser beam was guided through a 3 -fold beam expander and the process was carried out in air. Finally, laser-structured electrodes with a uniform porosity along the micro-pillars could be successfully manufactured. In comparison to laser ablation, embossing was supplementarily used for the adjustment of electrode porosity. During processing, an embossing tool was impressed into the manufactured electrode material (140 $\mu \mathrm{m} \pm 6 \mu \mathrm{m})$ until a defined film thickness of $100 \mu \mathrm{m} \pm 3 \mu \mathrm{m}$ was achieved. After relaxation, the electrodes offer porosities of $35 \% \pm 3 \%$ and $54 \% \pm 3 \%$. Fig. 2 shows schematically two NMC electrodes with different geometrical arrangements. Both types of electrodes were used for studying the lithium distribution at high charging and discharging C-rates.

\section{Cell assembly}

All cells were assembled in an argon-filled glove box (LABmaster sp, MBraun Inertgas-Systeme $\mathrm{GmbH}$, Germany, $\mathrm{H}_{2} \mathrm{O}<0.1 \mathrm{ppm}$ and $\mathrm{O}_{2}<0.1 \mathrm{ppm}$ ) using the Swagelok ${ }^{\circledR}$ cell design consisting of two plungers (stainless steel), three Swagelok® components (product number: SS-12M0-6, stainless steel), one spring (stainless steel), four sealing rings (polytetrafluoroethylene, PTFE), and $25 \mu \mathrm{m}$ thick polyimide foil (PI-foil) which acts as an isolator in order to prevent a short circuit. Both electrodes, $350 \mu \mathrm{m}$ thick metallic lithium foil (Sigma Aldrich Chemistry,

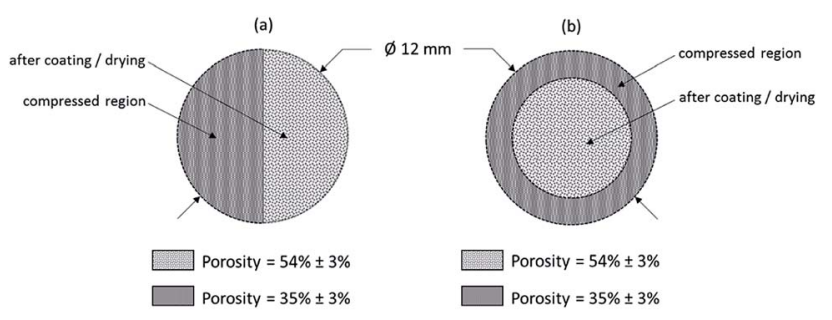

Fig. 2 Schematic diagram of NMC electrodes with variable porosity regions: (a) half-embossed NMC electrode and (b) NMC electrode with circular compression. The porosity regions were calculated to a value of $35 \% \pm 3 \%$ (compressed region) and $54 \% \pm 3 \%$ (after coating/drying).
USA) and the manufactured NMC thick film (MTI Corporation, USA) were placed between both plungers, separated by a $260 \mu \mathrm{m}$ glass micro-fiber film (GF/A, GE Healthcare UK Limited, UK). The liquid electrolyte (LP30) was purchased from Sigma Aldrich Chemistry and contains a solution of one molar lithium hexafluorophosphate conducting salt $\left(1 \mathrm{~mol} \mathrm{LiPF}_{6}\right)$ in ethylene carbonate (EC)/dimethyl carbonate (DMC), $1: 1$ by volume. Prior to cell assembly, all NMC electrodes were cut using an ultrafast laser into circular disks of $12 \mathrm{~mm}$ in diameter and were further dried in a vacuum oven (VT 6025, Thermo Scientific, Germany) at $120{ }^{\circ} \mathrm{C}$ for $24 \mathrm{~h}$.

\section{Electrochemical investigation}

For the quantitative evaluation of the lithium concentration in unstructured, embossed, and laser-structured NMC electrodes, battery tests were carried out in a voltage range of 3.0-4.2 V using a BT2000 battery cycler (Arbin Instruments, USA). In total, five NMC electrodes with various surface topographies and porosity regions were electrochemically cycled as shown in Table 1. During the first step, electrochemical formation was performed on samples 2-6 applying a C-rate of 0.1C for three cycles. Subsequently, cells with samples 3-6 were selected for further electrochemical cycling (step 2). The C-rate for charging and discharging was varied from $0.5 \mathrm{C}$ to $2 \mathrm{C}$. After electrochemical characterization, all cells were disassembled, washed two times for 30 minutes each in fresh DMC and subsequently investigated by LIBS.

\section{LIBS instrumentation and chemical analysis}

Within the scope of these investigations, a FiberLIBS System (SN013, SECOPTA analytics GmbH, Germany) was used for quantitative analysis of the lithium concentration within NMC thick film electrodes. The experimental setup of LIBS is described elsewhere. ${ }^{31}$ Briefly, a pulsed passive mode-locked diode pumped solid state Nd:YAG micro-chip laser was used, which operated at $1064 \mathrm{~nm}$ wavelength, delivering laser pulses of $1.5 \mathrm{~ns}$ at a repetition rate of $100 \mathrm{~Hz}$. The laser-beam was focused with a $75 \mathrm{~mm}$ focal length lens onto an electrode sample surface generating laser-induced plasma. The plasma emission was collected and further directed through an optical fiber bundle into two AvaSpec fiber-optic spectrometers (AvaSpec-ULS2048XL-2-USB2, Avantes, Netherlands). Both spectrometers were developed in a symmetrical Czerny-Turner design and offer a spectral range from 229 to $498 \mathrm{~nm}$ and 569 to $792 \mathrm{~nm}$, respectively. Equipped with a ruled grating of 1200 grooves per $\mathrm{mm}$ blazed at $250 \mathrm{~nm}$, the output of the spectrometer was coupled to a back-thinned charge-coupled detector (CCD) including an electronic shutter function (S11155, Hamamatsu, Japan). The CCD sensors each have an image area of $2048 \times 2048$ pixels and a pixel width of $14 \mu \mathrm{m}$, and were used to detect the dispersed light from the laserinduced plasma. Spatially resolved 3D elemental imaging with LIBS was performed by scanning the electrodes across three axes $(X, Y, Z)$. In the $X$ - and $Y$-directions, the electrodes were analyzed by applying a dot matrix with a lateral resolution of $100 \mu \mathrm{m}$. For the characterization of the entire electrode surface, 
Table 1 Electrochemical testing procedure and LIBS analysis for Swagelok® cells with unstructured, embossed, and laser-structured NMC thick film electrodes

\begin{tabular}{|c|c|c|c|}
\hline \multirow{2}{*}{ Sample } & Step 1 & Step 2 & Step 3 \\
\hline & $\frac{\text { Electrochemical }}{\text { formation }}$ & $\begin{array}{l}\text { Galvanostatic } \\
\text { measurements }\end{array}$ & $\begin{array}{c}\text { Laser-induced } \\
\text { breakdown spectroscopy }\end{array}$ \\
\hline $\begin{array}{l}\text { Unstructured } \\
\text { NMC electrode }\end{array}$ & - & - & \\
\hline $\begin{array}{l}\text { Unstructured } \\
\text { NMC electrode }\end{array}$ & $\begin{array}{l}\text { Cell design: } \\
\text { Swagelok }^{\bullet}\end{array}$ & - & \\
\hline \multirow{2}{*}{$\begin{array}{l}\text { Unstructured } \\
\text { NMC electrode } \\
\text { (Sample 3) }\end{array}$} & \multirow{2}{*}{$\begin{array}{l}\text { Counter electrode: } \\
\text { Lithium }\end{array}$} & $\begin{array}{c}\text { C-rate: } \\
\text { charging: } 0.5 \mathrm{C} \\
\text { discharging: } 0.5 \mathrm{C}\end{array}$ & \\
\hline & & $\begin{array}{c}\text { Number of cycles: } \\
100 \text { (cycle 93: cell failure) }\end{array}$ & \\
\hline \multirow{2}{*}{$\begin{array}{l}\text { Embossed } \\
\text { NMC electrode } \\
\text { (Sample 4) }\end{array}$} & \multirow{2}{*}{$\begin{array}{c}\text { Electrolyte: } \\
\text { EC:DMC 1:1, 1mol LiPF } 6 \\
\\
\text { Separator: } \\
\text { Glass fiber }\end{array}$} & $\begin{array}{c}\text { C-rate: } \\
\text { charging: } 0.5 \mathrm{C} \\
\text { discharging: } 1 \mathrm{C}\end{array}$ & \\
\hline & & $\begin{array}{c}\text { Number of cycles: } \\
200 \text { (cycle 66: cell failure) }\end{array}$ & \\
\hline \multirow{2}{*}{$\begin{array}{l}\text { Embossed } \\
\text { NMC electrode } \\
\text { (Sample 5) }\end{array}$} & \multirow{2}{*}{$\begin{array}{c}\text { C-rate: } \\
\text { Charging: } 0.1 \mathrm{C} \\
\text { Discharging: } 0.1 \mathrm{C} \\
\\
\text { Voltage range: } \\
3.0 \mathrm{~V}-4.2 \mathrm{~V}\end{array}$} & $\begin{array}{c}\text { C-rate: } \\
\text { charging: } 0.5 \mathrm{C} \\
\text { discharging: } 1 \mathrm{C}\end{array}$ & \\
\hline & & $\begin{array}{l}\text { Number of cycles: } \\
200 \text { (cycle 146: cell failure) }\end{array}$ & \\
\hline \multirow{2}{*}{$\begin{array}{l}\text { Laser-structured } \\
\text { NMC electrode } \\
\text { (Sample 6) }\end{array}$} & \multirow{2}{*}{ Number of cycles: 3} & $\begin{array}{c}\text { C-rate: } \\
\text { charging: } 2 \mathrm{C} \\
\text { discharging: } 2 \mathrm{C}\end{array}$ & \\
\hline & & $\begin{array}{l}\text { Number of cycles: } \\
146 \text { (stopped) }\end{array}$ & \\
\hline
\end{tabular}

the measurement area was adjusted to $13 \times 13 \mathrm{~mm}^{2}$, which corresponds to $131 \times 131=17161$ recorded spectra (Fig. 3a). In the $Z$-direction, elemental depth profiling was carried out layerby-layer. Depending on the electrode porosity, ablation craters with a depth of 4-6 $\mu \mathrm{m}$ were formed after each laser pulse. Here, the measurement area was set depending on the investigation as depicted in Fig. 3b-d.

\section{Inductively coupled plasma-optical emission spectroscopy}

Inductively coupled plasma-optical emission spectroscopy (ICPOES, OPTIMA 4300 DV, PerkinElmer, USA) was performed as a chemical analysis technique for the quantitative investigation of lithium. During chemical characterization, approximately $3 \mathrm{mg}$ of composite material was dissolved in a solution consisting of $5 \mathrm{ml}$ nitric acid, $1 \mathrm{ml}$ hydrofluoric acid, $1 \mathrm{ml}$ sulfuric acid and $1 \mathrm{ml}$ perchloric acid. The measurements were carried out for 35 minutes at a temperature of $210{ }^{\circ} \mathrm{C}$, using a microwave oven (Speedwave Xpert, Berghof, Germany). The analysis of the elements was accomplished using four different calibration solutions and two internal standards ( $\mathrm{Na}$ and $\mathrm{Sc}$ ). The error of measurement for $\mathrm{Li}$ is $2.5 \%$.
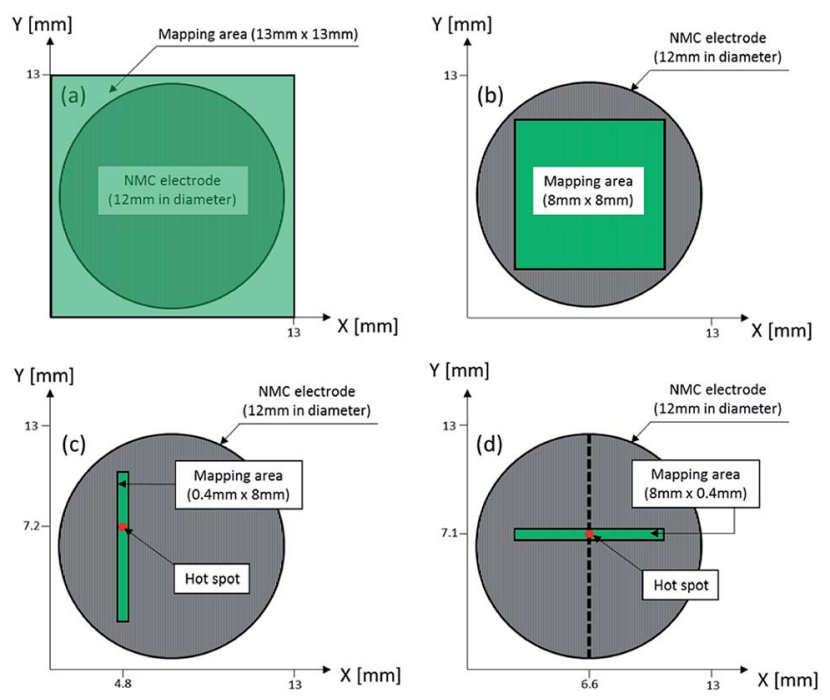

Fig. 3 Mapping dimensions for LIBS measurements of thick film NMC electrodes: (a) $13 \mathrm{~mm} \times 13 \mathrm{~mm}$, (b) $8 \mathrm{~mm} \times 8 \mathrm{~mm}$ (c) $0.4 \mathrm{~mm} \times 8 \mathrm{~mm}$ and (d) $8 \mathrm{~mm} \times 0.4 \mathrm{~mm}$. 


\section{Results and discussion}

\section{LIBS calibration by partial least squares regression}

For quantitative investigation of lithium concentration and its distribution in electrochemically cycled NMC thick electrodes, the LIBS-system was calibrated by applying a multivariate calibration technique, "Partial Least Squares Regression”. Based on reference samples of known composition, this kind of calibration approach allows the identification of element concentration and distribution by rapid processing of the acquired data. ${ }^{33}$ In this work, nine individual NMC electrodes - all incorporating the same and known cathode composition - were respectively electrochemically cycled and held at various voltages in a range from 3.0-5.0 $\mathrm{V}$ without formation. A holding step was performed for achieving a homogeneous state-of-charge within each electrode. The homogeneity of lithium concentration and distribution at various states-of-charge $(3.0 \mathrm{~V}$ and $5.0 \mathrm{~V})$ is presented elsewhere. ${ }^{34}$ Due to the fact that electrolyte decomposition may appear at voltages above $4.5 \mathrm{~V},{ }^{35}$ the electrical current was recorded for each cell as a function of time. Based on the results for electrochemical titration at $5 \mathrm{~V}$ (not shown here), it could be observed that the electrical current increases after 6080 hours. This rise in electrical current can be assigned to electrolyte decomposition. In order to avoid significant influence of electrolyte decomposition, all cells were held at the preset voltages for a defined time of 50 hours. Finally, the cells were disassembled, washed two times for 30 minutes each in fresh DMC and bisected by ultrafast laser cutting. One part of the electrode was chemically analyzed by ICP-OES, and the other part was used as a teaching-set for LIBS measurement (Fig. 4a). In a first approach, the teaching-set was configured by recording the lithium peak intensity at $610.4 \mathrm{~nm}$ for each calibration sample in the range from 3.0-5.0 V. Six laser pulses were applied at 16 different measurement locations for the quantitative investigation of the lithium amount $x$ in $\mathrm{Li}_{x}\left(\mathrm{Ni}_{1 / 3} \mathrm{Mn}_{1 / 3} \mathrm{Co}_{1 / 3}\right) \mathrm{O}_{2}$ as a function of their pre-set voltage. The first laser pulse was used as a cleaning step. As shown in Fig. 4 b, the lithium concentration $x$ in $\mathrm{Li}_{x}\left(\mathrm{Ni}_{1 / 3} \mathrm{Mn}_{1 / 3} \mathrm{Co}_{1 / 3}\right) \mathrm{O}_{2}$ decreases when increasing the voltage up to $5.0 \mathrm{~V}$. Furthermore, two characteristic drops in the titration curve can be identified. The first drop is located at a voltage of $3.8 \mathrm{~V}$ and the second one is located at $4.6 \mathrm{~V}$. These changes in curvature slope correspond to electrochemical redox couples $\mathrm{Ni}^{2+/ 4+}$ and $\mathrm{Co}^{3+/ 4+}$, indicating that the lithium deintercalation from the host lattice mainly occurs at $3.6-3.8 \mathrm{~V}$ and $4.55-4.65 \mathrm{~V}$, respectively. ${ }^{36}$ Based on the calibration procedure using ICP-OES, a standard deviation of $x$ in $\mathrm{Li}_{x}\left(\mathrm{Ni}_{1 / 3} \mathrm{Mn}_{1 / 3} \mathrm{Co}_{1 / 3}\right) \mathrm{O}_{2}$ was achieved in the range of 0.002 (at $5.0 \mathrm{~V}$ ) -0.047 (at $3.0 \mathrm{~V}$ ).

\section{D elemental imaging of NMC thick films}

Unstructured NMC electrodes. For unstructured NMC electrodes, quantitative LIBS measurements were carried out on the electrodes after manufacturing, electrochemical formation and galvanostatic measurements, respectively (see Table 1). For each electrode (Fig. 5a, c, and e), 16 layers were recorded in a geometrical dimension of $13 \mathrm{~mm} \times 13 \mathrm{~mm}$ (Fig. 3a). The ablation depth for each layer was measured to an average value (a)

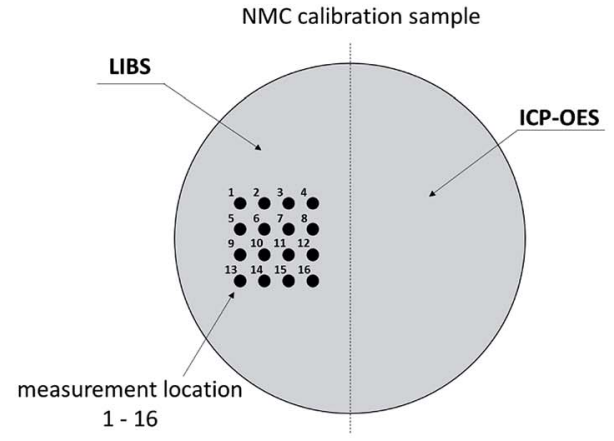

(b)

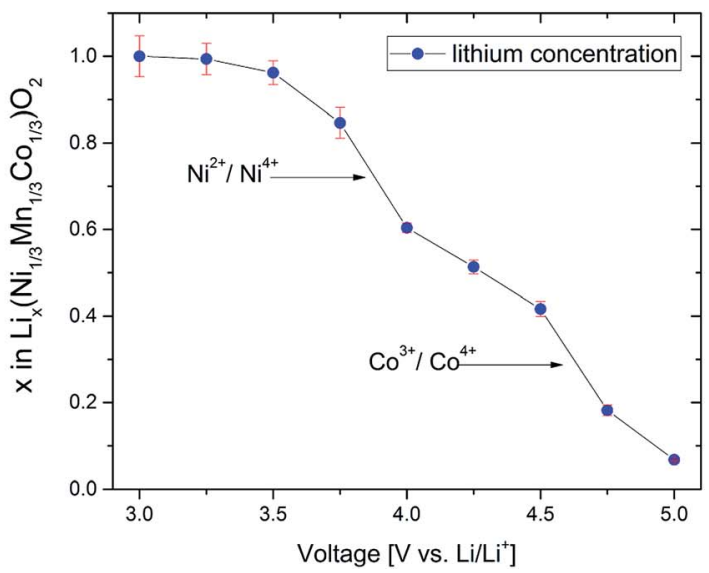

Fig. 4 Preparation steps prior to quantitative elemental imaging: (a) schematic diagram of a bisected calibration sample for subsequent LIBS and ICP-OES measurements and (b) adjustment of nine defined states-of-charge in the voltage range of 3.0-5.0 $\mathrm{V}$ by electrochemical titration.

of $5 \mu \mathrm{m}$. As shown in Fig. 5b, a homogeneous lithium distribution was achieved after electrode manufacturing. The mapping area for cross-sectional view was set to $8 \mathrm{~mm} \times 8 \mathrm{~mm}$ (Fig. 3b). Along the $Y$-direction, the averaged lithium concentration $x$ in $\mathrm{Li}_{x}\left(\mathrm{Ni}_{1 / 3} \mathrm{Mn}_{1 / 3} \mathrm{Co}_{1 / 3}\right) \mathrm{O}_{2}$ was plotted for all layers as a function of the $X$-direction. For layer 4,6 , and 8 , the $x$ in $\mathrm{Li}_{x}$ values of $1.090 \pm 0.010,1.086 \pm 0.009$, and $1.082 \pm 0.012$ could be measured. After electrochemical formation, no significant changes in lithium distribution could be detected, which indicates a uniform intercalation/deintercalation of lithium-ions during battery operation at low C-rates, i.e., C/10. In comparison to electrodes after manufacturing, the averaged lithium concentration $x$ in $\mathrm{Li}_{x}\left(\mathrm{Ni}_{1 / 3} \mathrm{Mn}_{1 / 3} \mathrm{Co}_{1 / 3}\right) \mathrm{O}_{2}$ could now be measured to be $1.076 \pm 0.012,1.079 \pm 0.014$, and $1.071 \pm$ 0.0095 for layer 4,6 , and 8 (Fig. $5 \mathrm{~d}$ ).

Fig. 5e shows an elemental map of lithium (mapping dimension shown in Fig. 3c), recorded from an unstructured electrode after spontaneous cell failure after cycle 93 (Fig. 6). The electrode indicates inhomogeneous lithium distribution with a local increased accumulation of lithium-ions at the electrode surface $(X=4.8 \mathrm{~mm}$ and $Y=7.2 \mathrm{~mm}$ ). This enhanced lithium concentration - here also denoted as "hot spot" - can be detected in each layer, measured from the electrode surface down to layer 


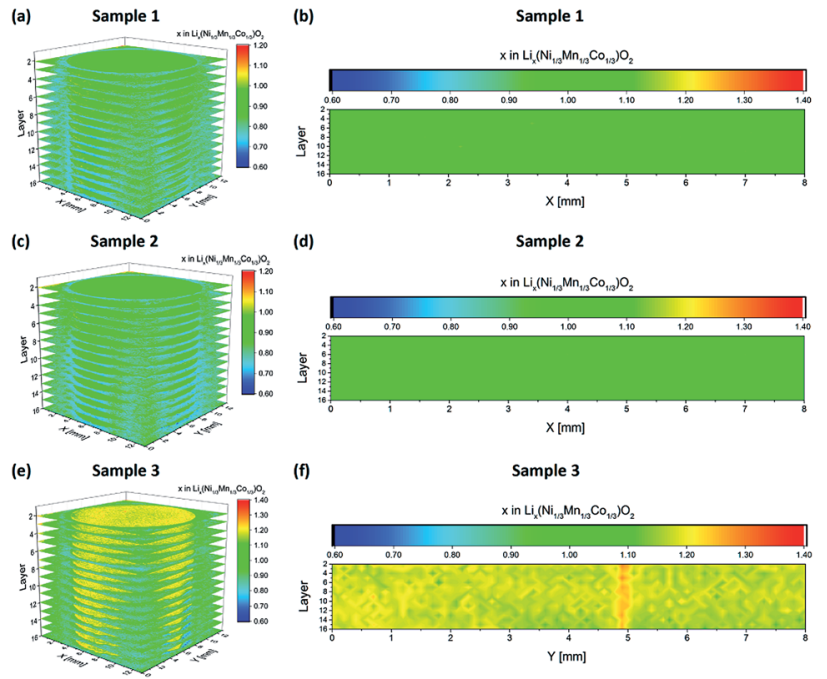

Fig. $5 \mathrm{Li}$ concentration profiles (3D and cross sectional view) of unstructured NMC thick film electrodes achieved by LIBS. (a and b) After coating, (c and d) after electrochemical formation, and (e and f) after galvanostatic cycling (see Table 1).

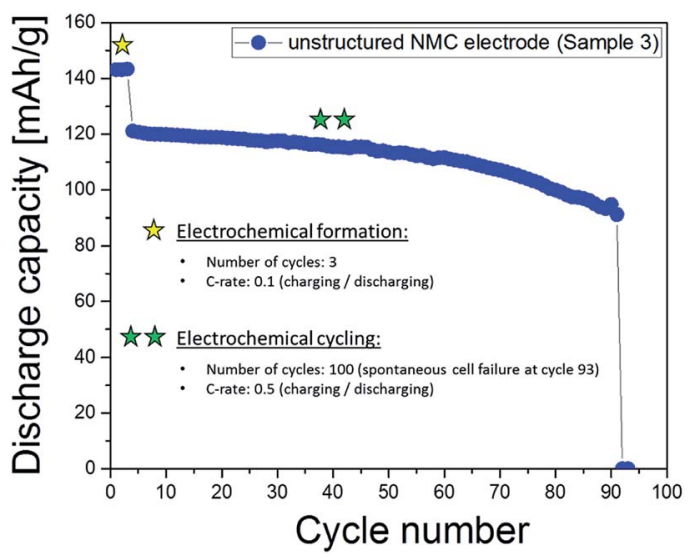

Fig. 6 Galvanostatic measurement of a cell with an unstructured NMC thick film electrode. The discharge capacity is plotted as a function of cycle number. The electrochemical procedure is shown in Table 1.

16 (Fig. 5f). One possible cause for this kind of hot spot with increased lithium concentration $x$ in $\mathrm{Li}_{x}\left(\mathrm{Ni}_{1 / 3} \mathrm{Mn}_{1 / 3} \mathrm{Co}_{1 / 3}\right) \mathrm{O}_{2}$ (layer 4: $x=1.166 \pm 0.005$; layer $6: x=1.168 \pm 0.006$; layer 8: $x=1.175 \pm 0.007$ ) can be explained by a local inhomogeneity in current density during electrochemical cycling. This in turn might be induced by inhomogeneities in porosity, material composition, material (active material, binder and conductive agents) distribution, and inhomogeneous liquid electrolyte wetting. In the manufacturing of lithium-ion batteries, electrolyte filling and warm aging processes are critical operation steps, which influence the electrochemical performance of a battery, especially by using electrodes with large footprint areas and thicknesses larger than or equal to $100 \mu \mathrm{m} .{ }^{17,20}$ Consequently, an adequate wetting of electrodes with liquid electrolyte is one of the essential process strategies for avoiding chemical degradation leading to the formation of the so-called hot spots.
Embossed NMC electrodes. Two electrode designs were partially generated via embossing (Fig. 2a and b) for studying the impact of porosity variations within the electrode. As shown in Fig. 7, low and high porosity regions could be successfully manufactured, providing porosity values of $35 \% \pm 3 \%$ for embossed electrodes and $54 \% \pm 3 \%$ for the as-deposited electrodes. However, both types of electrodes (sample 4 and 5) suffered from spontaneous cell failure during battery operation at cycle 66 and cycle 146 (see Table 1). For quantitative investigation of lithium distribution post-mortem LIBS measurements were performed. 3D elemental imaging of lithium was performed by screening the entire electrode layer-by-layer. As illustrated in Fig. 8a, a total number of ten layers were recorded for sample 4. The mapping dimension was set to $13 \mathrm{~mm} \times$ $13 \mathrm{~mm}$ (Fig. 3a). It can be clearly seen that embossing leads to material compaction with reduced open porosity at the surface, which in turn will also have an impact on the entire porosity. Additionally, an increase in lithium concentration was detected at the electrode surface (Fig. 8b), located at the interface between the low and high porosity region $(X=6.6 \mathrm{~mm}$, $Y=7.1 \mathrm{~mm}$ ). This local increase of lithium concentration was observed on each layer (Fig. 8c), recorded from the electrode surface down to layer 10 . Here, the mapping dimension was adjusted to $8 \mathrm{~mm} \times 0.4 \mathrm{~mm}$ (Fig. 3d). In addition, Fig. 8d illustrates an accumulation of lithium-ions, observed in the low porosity regions. The mapping dimension was set to $8 \mathrm{~mm} \times$ $8 \mathrm{~mm}$ corresponding to Fig. $3 \mathrm{~b}$ and the average concentration values for lithium are shown in Table 2 . Depending on the porosity, two regions were defined: the first region $(X=0-3.5$ $\mathrm{mm})$ with low porosity $(35 \% \pm 3 \%)$ and the second region $(X=$ $4.5-8 \mathrm{~mm})$ with high porosity $(54 \% \pm 3 \%)$. Finally, Fig. $8 \mathrm{e}$ represents a trend for lithium concentration measured for an illustrated area of Fig. 8d (see inlay). For layers 2-6, the lithium concentration is plotted as an averaged value in the $Y$-direction for $X=2-6 \mathrm{~mm}$. It could be observed that for $X=4.5-6 \mathrm{~mm}$ (high porosity regions) the lithium concentration is increased at the surface of the electrode (layer 1 and 2) while for low porosity regions $(X=2-3.5 \mathrm{~mm})$ there is no change in lithium concentration detected within the measurement accuracy (see error bars in Fig. 8e). For NMC electrodes with circular compression (Fig. 2b), post-mortem LIBS measurements were performed of the entire electrode. As shown in Fig. 9, an inhomogeneous lithium distribution could be observed for all layers. Similar to sample 4 (Fig. 8, half-embossed NMC electrode), an increased lithium concentration could be localized at the interface between high and low porosity regions $(X=8.1 \mathrm{~mm}$ and $Y=$ $9.4 \mathrm{~mm})$. We could identify that the increased lithium
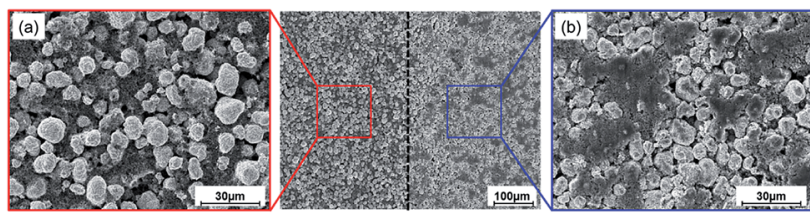

Fig. 7 SEM images of embossed electrodes: (a) electrode surface after manufacturing and (b) electrode surface after embossing. 
Sample 4

(a)

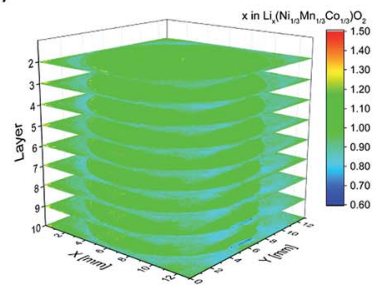

(b)

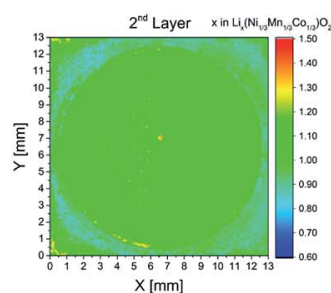

(c)

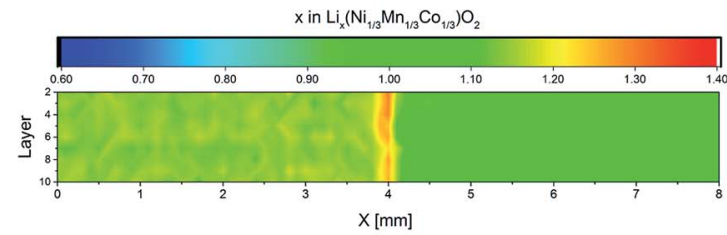

(d)

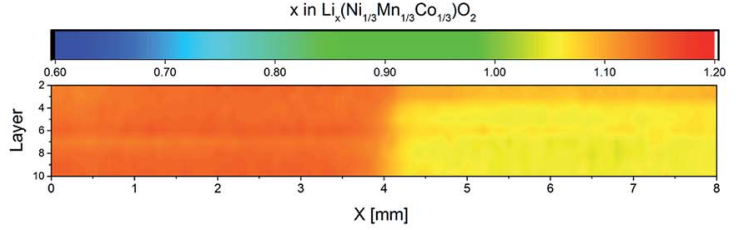

(e)

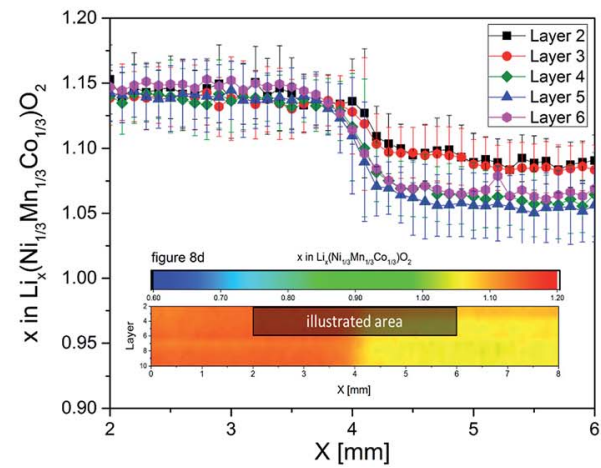

Fig. $8 \mathrm{Li}$ elemental mapping achieved from quantitative LIBS measurements on embossed NMC electrodes (sample 4) after electrochemical cycling: (a) 3D image of the entire electrode surface from layer 2 to layer 10 (layer 1 not shown here), (b) 2D elemental map of layer 2, (c) LIBS depth-profile (average $Y$-values) for layers 2-10 with a mapping area of $8 \mathrm{~mm} \times 0.4 \mathrm{~mm}$, (d) LIBS depth-profile (average $Y$ values) for layers 2-10 with a mapping area of $8 \mathrm{~mm} \times 8 \mathrm{~mm}$ and (e) gradient of lithium concentration (average $Y$-values) corresponding to (d) (illustrated area). The lithium concentration is plotted as a function of $X[\mathrm{~mm}]$ for layers $2-6$.

concentration $x$ in $\mathrm{Li}_{x}\left(\mathrm{Ni}_{1 / 3} \mathrm{Mn}_{1 / 3} \mathrm{Co}_{1 / 3}\right) \mathrm{O}_{2}$ (hot spot) stays almost constant from layer $2\left(x=1.34\right.$ in $\left.\mathrm{Li}_{x}\left(\mathrm{Ni}_{1 / 3} \mathrm{Mn}_{1 / 3} \mathrm{Co}_{1 / 3}\right) \mathrm{O}_{2}\right)$ up to layer $7\left(x=1.33\right.$ in $\left.\mathrm{Li}_{x}\left(\mathrm{Ni}_{1 / 3} \mathrm{Mn}_{1 / 3} \mathrm{Co}_{1 / 3}\right) \mathrm{O}_{2}\right)$. In the center of the electrode, the lithium concentration $x$ in $\mathrm{Li}_{x}\left(\mathrm{Ni}_{1 / 3} \mathrm{Mn}_{1 / 3} \mathrm{Co}_{1 / 3}\right)$ $\mathrm{O}_{2}$ reaches a minimum value of $x=1.06$ in layer 2 and $x=$ 0.98 in layer 7, while a lithium concentration of $x=1.2-1.3$ could be detected in the low porosity regions. As mentioned before, a well-defined porosity is quite necessary for electrochemical cyclability, particularly for NMC thick films operating in cells under high charging and discharging conditions.

To summarize, these compressed electrode surfaces provide an intrinsic porosity variation, which induces a local change in 
Sample 5

(a)

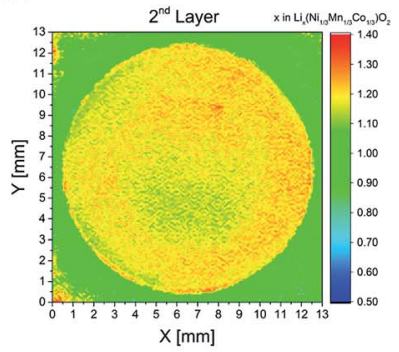

(c)

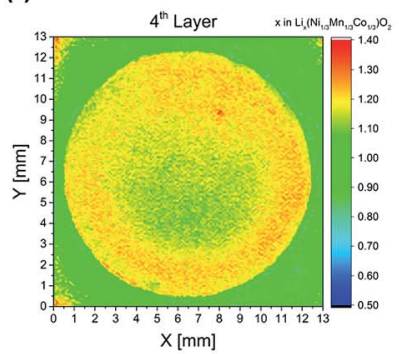

(e)

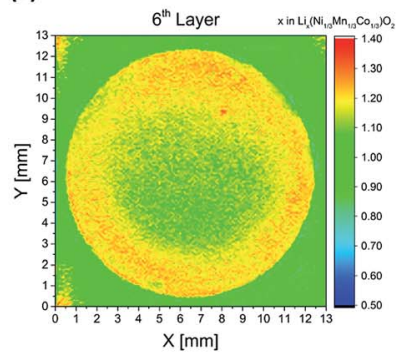

(b)

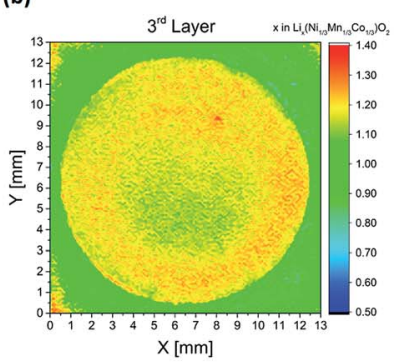

(d)

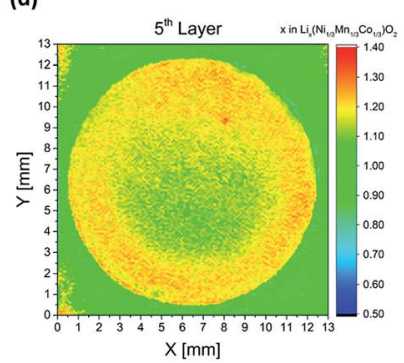

(f)

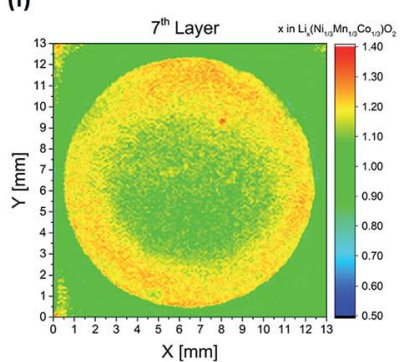

Fig. 9 Li elemental mapping achieved by LIBS of embossed NMC electrodes (sample 5) after electrochemical characterization: (a-f) Li maps for layers 2-7.

lithium distribution, indicating a dramatic chemically-driven aging process during battery operation. It is obvious that embossing, which could be easily performed during conventional calendering in battery manufacturing, is not a suitable structuring technology for the generation of 3D electrodes, which were already successfully established by laser ablation..$^{25-27}$

Laser-structured NMC electrodes. For studying the impact of 3D NMC architectures on lithium distribution and chemical degradation, free-standing micro-pillars were generated by ultrashort (fs) laser ablation as shown in Fig. 10. Here, the composite material was removed down to the substrate, forming cubical micro-pillars with a geometrical shape of $600 \mu \mathrm{m} \times$ $600 \mu \mathrm{m} \times 100 \mu \mathrm{m}$ (Fig. 10a). For this type of electrode architecture, both an intrinsic and artificial porosity were realized due to laser ablation. Each micro-pillar offers porosity values of $35 \% \pm 3 \%$ and a film thickness of $100 \mu \mathrm{m} \pm 3 \mu \mathrm{m}$. The microscopic cross-sectional images (Fig. 10b) clearly show that no significant damage of the current collector occurs during fslaser structuring. Additionally, the pitch distance between each micro-pillar was set to $1200 \mu \mathrm{m}$. For this electrode design LIBS could be performed on individual 3D pillars. In a first approach, laser-structured electrodes were characterized by LIBS after

(a)

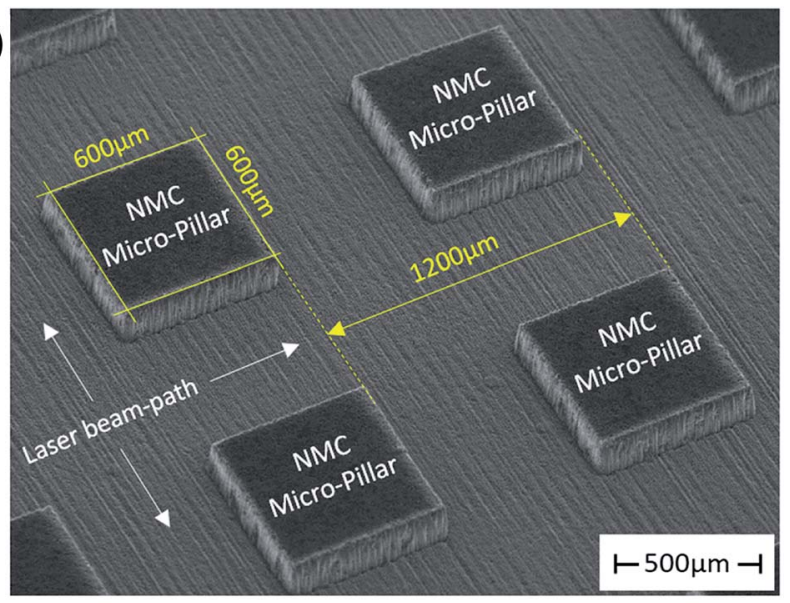

(b)
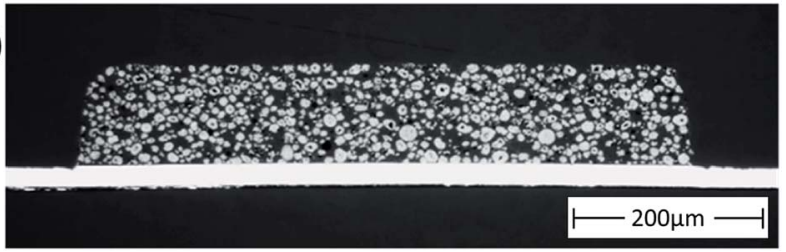

Fig. 10 SEM and microscope images of a laser-structured NMC thick film electrode: (a) top-view (SEM) and (b) cross-sectional view (microscope image).

manufacturing and fs-laser structuring. Fig. 11a and b clearly show that the lithium distribution is quite homogeneous in each free-standing micro-pillar and supplementary in very good accordance compared to unstructured electrodes after
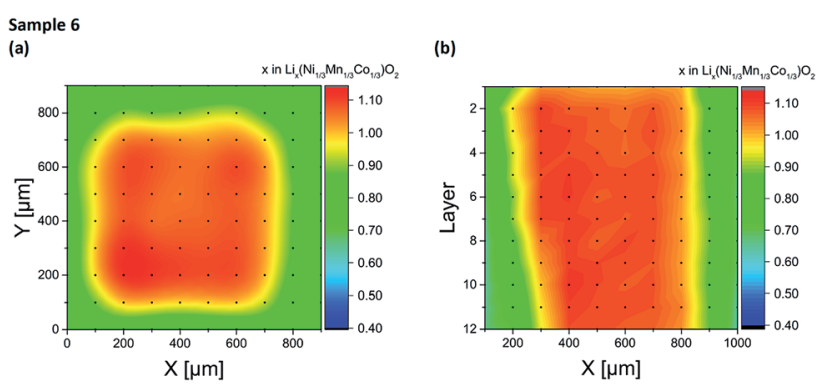

(c)
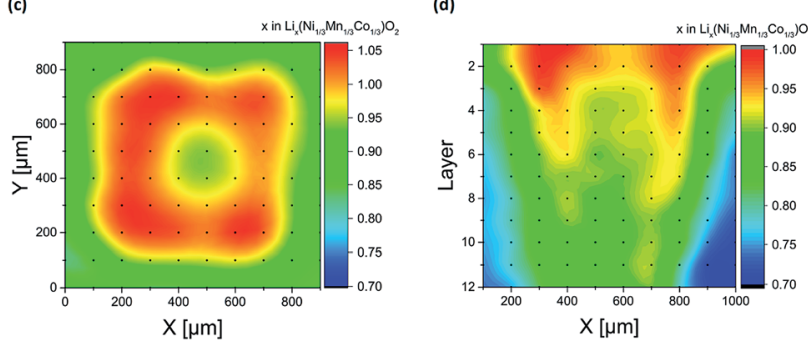

Fig. 11 Li elemental maps and Li depth-profiles of laser-generated micro-pillars in NMC thick film electrodes: ( $a$ and c) Li elemental maps of free-standing micro-pillars before and after electrochemical cycling (C-rate for charging and discharging: $2 \mathrm{C}-2 \mathrm{C}$ ), (b and d) Li elemental depth-profiles of NMC micro-pillars before and after electrochemical characterization (C-rate for charging and discharging: $2 \mathrm{C}-2 \mathrm{C}$ ). 
fabrication and prior to electrochemical cycling. After electrode manufacturing, all micro-pillars are completely lithiated, offering a lithium concentration of $x=1.07 \pm 0.030$. After battery operation (2C for charging and discharging), the lithium distribution in free-standing micro-pillars changed (Fig. 11c and d). Due to this type of surface and bulk analysis, it was possible to verify the $3 \mathrm{D}$ functionality of the fs-laser generated micro-features: the lithium concentration is significantly increased along the contour of each 3D micro-pillar. For the investigated micro-pillar shown in Fig. 11c, the maximum lithium concentration $x$ in $\mathrm{Li}_{x}\left(\mathrm{Ni}_{1 / 3} \mathrm{Mn}_{1 / 3} \mathrm{Co}_{1 / 3}\right) \mathrm{O}_{2}$ was measured at the surface to be 1.06, which indicates that free-standing micro-pillars lead to an increase of lithium mobility during battery operation under high power conditions. However, in the center of the micro-pillar, the lithium concentration $x$ reaches a minimum value of 0.93 . Thus, the lithium depleted region offers a circular area of $200 \mathrm{~mm}$ in diameter, which corresponds to $40 \%$ of the cubic micro-pillar. Due to the result in Fig. 11a and c a micro-pillar shape of $400 \mu \mathrm{m} \times 400 \mu \mathrm{m} \times 100 \mu \mathrm{m}$ is proposed for an optimized electrode architecture, providing a uniform lithium distribution under high power conditions. Finally, Fig. 11d shows a cross-sectional view of the micro-pillar, measured by LIBS. It can be shown so far that the lithium concentration further decreases in the middle of the freestanding micro-pillar from $x=0.93$ (pillar surface, $X=600$ $\mu \mathrm{m}$ ) down to $x=0.88$ (layer $12, X=600 \mu \mathrm{m}$ ). Depending on the C-rate (here $2 \mathrm{C}$ for charging and discharging) only a part of the micro-pillar is activated during battery operation. For layer 2, 4 and 6, $x$ in $\mathrm{Li}_{x}\left(\mathrm{Ni}_{1 / 3} \mathrm{Mn}_{1 / 3} \mathrm{Co}_{1 / 3}\right) \mathrm{O}_{2}$ values of $0.96,0.93$, and 0.93 (for $X=400 \mu \mathrm{m}$ ) and $0.98,0.95$, and 0.93 (for $X=800 \mu \mathrm{m}$ ) could be measured. All these results clearly show that $3 \mathrm{D}$ architectures need to be optimized regarding their lateral dimensions but also regarding their height as a function of the C-rate and intrinsic porosity in order to boost the battery performance for high power operation.

\section{Conclusions}

In this work, various types of NMC electrodes were manufactured by embossing and ultrafast laser structuring. The electrochemical performance was studied by galvanostatic measurements, and laser-induced breakdown spectroscopy (LIBS) was applied for the investigation of lithium distribution and its concentration within each type of NMC electrode. Additionally, the impact of electrode porosity on chemical degradation and battery lifetime was investigated. For unstructured NMC thick film electrodes, a local increase in lithium concentration, a so-called hot spot, could be detected after spontaneous cell failure. For electrodes with varying porosity on the macro-scale, a correlation between lithium distribution and enhanced cell degradation could be detected. In comparison to embossing, femtosecond laser patterning technology was proven to have a positive impact on battery performance and battery lifetime. Especially for high C-rates, this becomes an important issue leading to a measurable variation of lithium distribution along the surface of each cubic micro-pillar. In comparison to the former discussed hot spot formation, this type of lithium increase is quite smooth, occurs on the surface along lateral dimensions of about $400 \mu \mathrm{m}$, and does not have a negative impact on the cell lifetime. It could be clearly demonstrated by LIBS that the lithium concentration is also significantly increased along the contour of free-standing microstructures, which indicates that 3D architectures provide additional Li pathways leading to a significant increase of lithium mobility during battery operation under high power conditions. An optimized micro-pillar dimension can be derived from elemental mapping studies. Micro-pillars with a lateral dimension of about 300-400 $\mu \mathrm{m}$ seem to be optimal in order to avoid donut-like lithium distributions in high power operations which has to be verified in ongoing research.

\section{Conflicts of interest}

There are no conflicts to declare.

\section{Acknowledgements}

We are grateful to our colleagues H. Besser and J. Anhalt for their technical assistance during laser materials processing and LIBS. This project has received funding from the German Research Foundation (DFG, project No. 392322200). Finally, the support for laser materials processing from the Karlsruhe Nano Micro Facility (KNMF, http://www.knmf.kit.edu/), a Helmholtz research infrastructure at the Karlsruhe Institute of Technology (KIT), is gratefully acknowledged.

\section{References}

1 J. M. Foster, X. Huang, M. Jiang, S. J. Chapman, B. Protas and G. Richardson, J. Power Sources, 2017, 350, 140-151.

2 Y. Gao, J. C. Jiang, C. P. Zhang, W. G. Zhang, Z. Y. Ma and Y. Jiang, J. Power Sources, 2017, 356, 103-114.

3 M. Mathew, Q. H. Kong, J. McGrory and M. Fowler, J. Power Sources, 2017, 349, 94-104.

4 J. Schmitt, A. Maheshwari, M. Heck, S. Lux and M. Vetter, J. Power Sources, 2017, 353, 183-194.

5 R. Wagner, N. Preschitschek, S. Passerini, J. Leker and M. Winter, J. Appl. Electrochem., 2013, 43, 481-496.

6 S. J. An, J. L. Li, Z. J. Du, C. Daniel and D. L. Wood, J. Power Sources, 2017, 342, 846-852.

7 C. F. Chen, P. Barai, K. Smith and P. P. Mukherjee, Electrochim. Acta, 2016, 204, 31-49.

$8 \mathrm{~J}$. de Hoog, J. M. Timmermans, D. Ioan-Stroe, M. Swierczynski, J. Jaguemont, S. Goutam, N. Omar, J. Van Mierlo and P. van den Bossche, Appl. Energy, 2017, 200, 4761.

9 N. Nitta, F. X. Wu, J. T. Lee and G. Yushin, Appl. Energy, 2015, 18, 252-264.

10 B. Scrosati, J. Hassoun and Y. K. Sun, Energy Environ. Sci., 2011, 4, 3287-3295.

11 M. M. Thackeray, C. Wolverton and E. D. Isaacs, Energy Environ. Sci., 2012, 5, 7854-7863. 
12 I. V. Thorat, D. E. Stephenson, N. A. Zacharias, K. Zaghib, J. N. Harb and D. R. Wheeler, J. Power Sources, 2009, 188, 592-600.

13 D. Andre, S. J. Kim, P. Lamp, S. F. Lux, F. Maglia, O. Paschos and B. Stiaszny, J. Mater. Chem. A, 2015, 3, 6709-6732.

14 K. Amine, R. Kanno and Y. H. Tzeng, MRS Bull., 2014, 39, 395-405.

15 A. Manthiram, B. Song and W. Li, Energy Storage Materials, 2017, 6, 125-139.

16 M. Singh, J. Kaiser and H. Hahn, J. Electroanal. Chem., 2016, 782, 245-249.

17 W. Pfleging, Nanophotonics, 2017, 7, 549-573.

18 J. W. Long, B. Dunn, D. R. Rolison and H. S. White, Chem. Rev., 2004, 104, 4463-4492.

19 S. Ferrari, M. Loveridge, S. D. Beattie, M. Jahn, R. J. Dashwood and R. Bhagat, J. Power Sources, 2015, 286, 25-46.

20 W. Pfleging and J. Pröll, J. Mater. Chem. A, 2014, 2, 1491814926.

21 W. Xiong, Q. Y. Xia and H. Xia, Funct. Mater. Lett., 2014, 7, 1430003.

22 C. Meyer, H. Bockholt, W. Haselrieder and A. Kwade, J. Mater. Process. Technol., 2017, 249, 172-178.

23 H. H. Zheng, G. Liu, X. Y. Song, P. Ridgway, S. D. Xun and V. S. Battaglia, J. Electrochem. Soc., 2010, 157, A1060-A1066.

24 H. H. Zheng, L. Tan, G. Liu, X. Y. Song and V. S. Battaglia, J. Power Sources, 2012, 208, 52-57.
25 M. Mangang, H. J. Seifert and W. Pfleging, J. Power Sources, 2016, 304, 24-32.

26 J. Pröll, H. Kim, A. Piqué, H. J. Seifert and W. Pfleging, J. Power Sources, 2014, 255, 116-124.

27 J. H. Rakebrandt, P. Smyrek, Y. Zheng, H. J. Seifert and W. Pfleging, Proc. SPIE, 2017, 10092, 100920M1-100920M7.

$28 \mathrm{H}$. Hou and V. Zorba, IEEE (CLEO), 2014, 1-2.

29 H. M. Hou, L. Cheng, T. Richardson, G. Y. Chen, M. Doeff, R. Zheng, R. Russo and V. Zorba, J. Anal. At. Spectrom., 2015, 30, 2295-2302.

30 V. Zorba, J. Syzdek, X. L. Mao, R. E. Russo and R. Kostecki, Appl. Phys. Lett., 2012, 100, 234101-1-234101-5.

31 P. Smyrek, J. Pröll, H. J. Seifert and W. Pfleging, J. Electrochem. Soc., 2016, 163, A19-A26.

32 P. Smyrek, Y. Zheng, H. J. Seifert and W. Pfleging, Proc. SPIE, 2018, 10520, 1052017-1-1052017-7.

33 J. M. Andrade, G. Cristoforetti, S. Legnaioli, G. Lorenzetti, V. Palleschi and A. A. Shaltout, Spectrochim. Acta, Part B, 2010, 65, 658-663.

34 P. Gotcu, W. Pfleging, P. Smyrek and H. J. Seifert, Phys. Chem. Chem. Phys., 2017, 19, 11920-11930.

35 L. L. Zhang, Y. L. Ma, X. Q. Cheng, P. J. Zuo, Y. Z. Cui, T. Guan, C. Y. Du, Y. Z. Gao and G. P. Yin, Solid State Ionics, 2014, 263, 146-151.

36 K. M. Shaju, G. V. S. Rao and B. V. R. Chowdari, Electrochim. Acta, 2002, 48, 145-151. 